\title{
Computerised grinding procedure for large scale crankshaft machining
}

\author{
Zbigniew Siemiątkowski ${ }^{1, *}$ \\ ${ }^{1}$ Kazimierz Pulaski University of Technology and Humanities, Faculty of Mechanical Engineering, Stasieckiego 54, 26-600 Radom, \\ Poland
}

\begin{abstract}
The paper describes sequence of machining operations that leads to the desired quality of the produced crankshaft, as well as in-situ inspection, correction and compensation procedures performed and controlled by computer. The form deviation values after correction are being compared with those obtained before. In case of crank pins, values of form deviations, and hence those of corrections, are much larger than for main journals. During the measurement, the probe collects data from 3600 points per revolution, and then averaging procedure reduces data down to 360 points. There are several algorithms for data processing available, so the operator may choose the one most appropriate. Substantial difference between out-ofroundness values of main journals and crank pivot was registered. Before form compensation, the former was between 0.01 and $0.02 \mathrm{~mm}$, while the latter were in range 0.07-0.09 $\mathrm{mm}$. Program of grinding is parametric, i.e. at each stage of the process all values responsible for the tool movement undergo correction. The applied computer monitoring enabled to achieve the demanded quality of grinded surface, as well as dimensions and form deviations in the tolerances set by the product specifications. Form compensation procedure enabled to reduce peak-to-peak deviation from $30.37 \mu \mathrm{m}$ down to $8.14 \mu \mathrm{m}$.
\end{abstract}

\section{Introduction}

Crankshaft is a highly significant element of a marine engine, because its failure, especially during an operation in a storm, may lead to the life threat of the shipboard personnel and passengers [1]. That is why crankshaft is a subject of thorough failure analysis [2]. A critical step in manufacture of forged crankshafts is the grinding of its sidewalls [3]. Improper grinding was reported to be a source of misalignments in journals, high stress concentration, and high surface roughness [4]. Investigations were made on the internal stresses in large size crankshafts after grinding [5] and its elastic deformations [6]. Interesting results were reported on the application of Huang-Hilbert transform to cutting conditions monitoring to assess the working conditions of cutting tools, and to make proper selection of cutting parameters [7].

The crankshafts of monolithic type, designed for the high-power marine diesel engines, are of length ca. $12 \mathrm{~m}$ and of weight ca. 25 tons. Customer sets very high demand on a surface topography with $R a<0.3 \mu \mathrm{m}$, which is almost impossible to obtain with the grinding technology. Therefore, hand polishing is applied after grinding. Typically, achievable $R a$ parameter after grinding is between 0.5 and $1.4 \mu \mathrm{m}$, while after polishing it lays between 0.1 and $0.3 \mu \mathrm{m}$ [8]. However, hand polishing has very limited impact on the surface, so the grinding process must prepare the surface as efficiently as possible. The study is dedicated to the automated grinding process and inspection procedures performed by the computerised system MARPOSS.

\section{Grinding process}

The examined grinding process was performed with a grinder DB12500 type, equipped with the control system Sinumerik 840D, measurement system MARPOSS and eccentric machining system PENDULUM. The block diagram that explains the place of grinding procedure between other technological operations is shown in Figure 1.

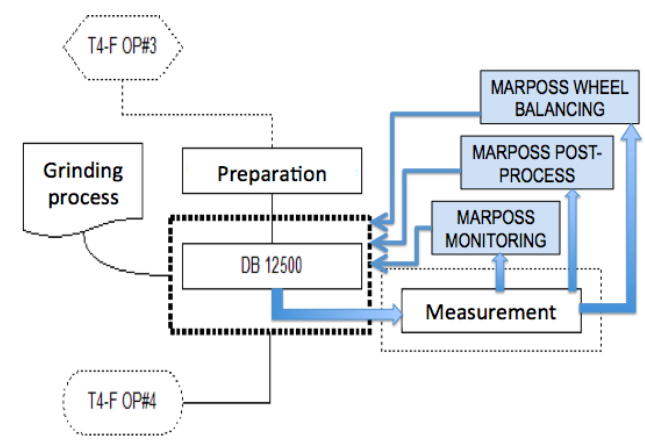

Fig. 1. Block diagram of the grinding. Explained in the text.

Preceding and subsequent operations \#3 and \#4 are performed on Turning and Milling Centre T4F. Operation \#3 consists of finishing of outer surfaces of the supporting flank and drilling holes in it. Operation \#4 after grinding consists of drilling of perpendicular oil

*Corresponding author: z.siemiatkowski@uthrad.pl 
ducts inside the pivots. Preparation of the crankshaft to the grinding procedure contains following actions:

- cleansing the crankshaft surface, removing chips from inside of the holes,

- measurement of pivots diameters to determine the actual allowances to be removed,

- additional supporting elements are fixed on both ends of the crankshaft,

- preparation and check of the gauge pivot and measurement devices,

- calibration of supporting pivots.

In the process, the main journals were to be grinded first (main axis of the crankshaft), so the final dimensions were achieved, and then the crank-pins were grinded. In general, the grinding process can be described as follows:

- The initial grinding allowances of the diameter were ca. $1 \mathrm{~mm}$, maximally up to $1.5 \mathrm{~mm}$. It was more desirable to leave larger allowances on the crank-pins, to avoid increased uncertainty when an angle of a reference crank-pin was measured.

- After initial grinding of all the main journals, the fine grinding was initiated.

- The allowance for the fine grinding was ca. 0.3-0.4 mm on diameter.

- Supporting tailstocks are always put down under the grinded main journal. After grinding, the journal is again supported, and the position of the crankshaft is corrected on the base of flexometer indications.

- High pressure washing of the grinding disc after each operation is performed to prolong durability of the tool.

It is crucial that, after the initial grinding of all the main journals, measurements with MARPOSS device are made, and form corrections are performed. The final grinding commences only after the main axis accuracy is assured.

The applied system MARPOSS consists of three main units:

- Automatic system MARPOSS WHEEL BALANCING designed to continually supervise the balance of the grinding disc while it is in motion (Fig. 2, left).

- The main measurement system MARPOSS POSTPROCESS designed to measure form deviations of the main journals and crank-pins. The unit has three supporting points and the specially constructed arm, FENAR-L, which enables measurement of both main journals and crank-pins. The sensor collects 3600 points per rotation and is synchronised with the control system SINUMERIK 840D. The measured values are averaged down to 360 points using one of delivered algorithms. These points are the basis for the form compensation table correlated with the angle position of the measured pivot. The form correction is performed using the perpendicular support with defined virtual axis. Resolution of the device is $0.001 \mathrm{~mm}$.

- The third unit is a MARPOSS MONITORING equipped with the ultrasonic microphones (Fig. 2, right). It is designed to monitor the slot between grinding disc and grinded material (the GAP function) to control the contact between the tool and the ground material.
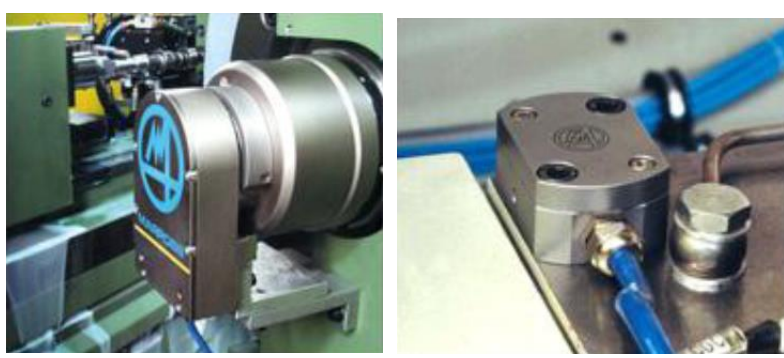

Fig. 2. Marposs Wheel Balancing (left) and Marposs Monitoring (right) systems.

\section{Measurement and control algorithm}

There are many methods for roundness assessment, among them CMM measurement [9] and non-contact air gauging [10]. For the specific task of large size crankshaft grinding, the MARPOSS system was chosen.

Before the grinding process is initiated, data appropriate for each grinded crankshaft should be uploaded. These are as follows:

- values of the angle position for each crank,

- offset values required for transposition of the coordinate system on the main journals and crank pivots,

- values into the Marposs measurement system that determine PART NO and CYCLE NO defined for each subsequent diameter,

- actual values of the pivot diameters before the grinding is started.

The pivot grinding program is a parametric one, which means that the values responsible for the tool's movement sequence underwent configuration at each stage of the process. Typical algorithm is as follows:

- grinding disc is moved to the base position (command HOME),

- disc rotation in turned on, typically $210 \mathrm{rev} / \mathrm{min}$,

- shaft rotation is turned on, typically $4 \mathrm{rev} / \mathrm{min}$,

- accelerated movement of the grinding disc toward the pivot to be machined, to the distance $100 \mathrm{~mm}$,

- further movement toward the pivot at speed $10 \mathrm{~mm} / \mathrm{rev}$, to the distance $3 \mathrm{~mm}$,

- the measurement arm Fenar-L is moved down to the working position (optional),

- the arm feeding a coolant to the disc is moved down,

- the gap control function is turned on automatically (command GAP/MARPOSS),

- further movement of the disc toward the pivot with the speed $0.2 \mathrm{~mm} / \mathrm{rev}$, to the distance $0.2 \mathrm{~mm}$,

- reduced speed movement $(0.05 \mathrm{~mm} / \mathrm{rev})$ is performed up to the contact with the pivot.

After the grinding disc got in contact with the machined pivot, software deletes the remaining path. The window appears, where the parameters of subsequent machining are shown. It presents information on the actual position of the tool in the axes $\mathrm{X}$ and Z, feeding parameters information, offset information on correction of the grinded length etc.

Next, the grinding depth is defined as an incremental value, and a working cycle starts with the feeding speed of $0.03 \mathrm{~mm} / \mathrm{rev}$. This operation is an initial machining which should be continued until the remained allowance 
is reduced to ca. $0.03 \mathrm{~mm}$ of the pivot diameter. The process must ensure continuous removal of material throughout entire circular perimeter of pivot. This is monitored by the digital oscilloscope installed on the panel Marposs/P7. This way the pivot is grinded on its entire length.

When the process is finished, the grinding disc is quickly put away from the pivot (distance $1 \mathrm{~mm}$ ), so the measurement of form deviation can be made. Then the measuring arm Fenar-L is moved down to the working position, and the measurement is performed. After the measurement, it goes back to the position HOME.

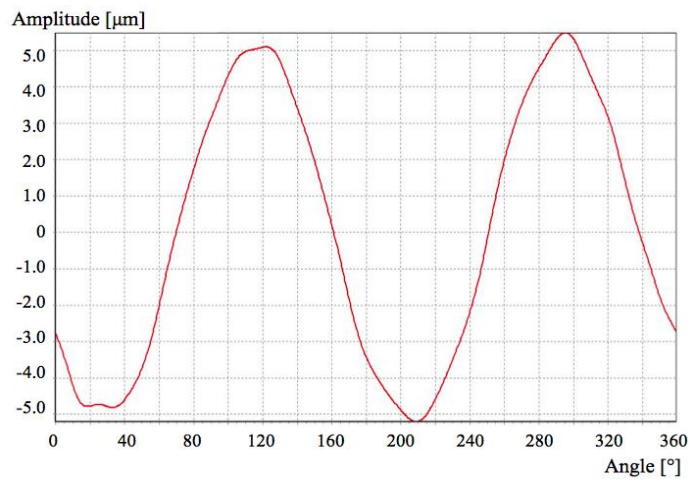

Fig. 3. Main journal form deviation measurement before form correction in orthodox coordinates.

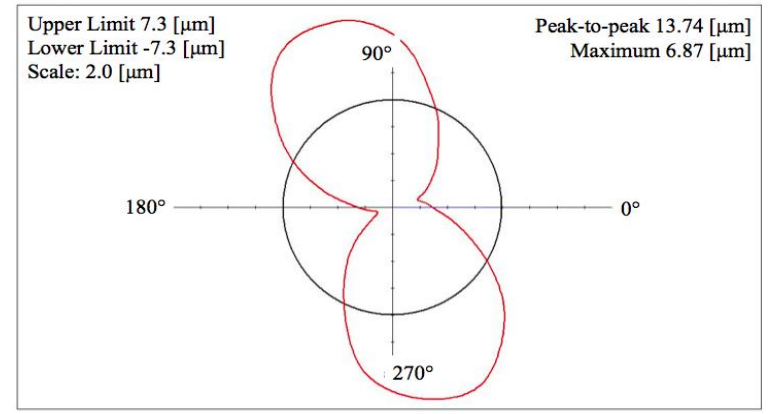

Fig. 4. Main journal form deviation measurement before form correction in radial coordinates.
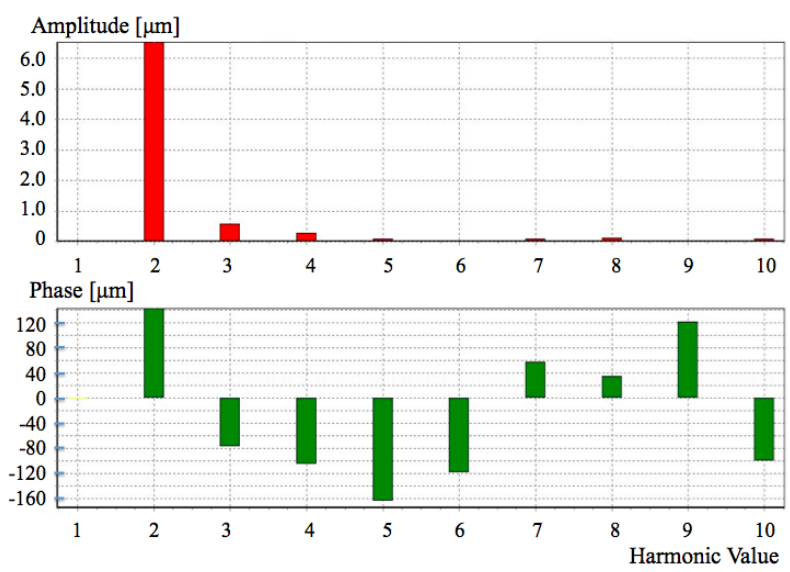

Fig. 5. Main journal form deviation harmonic analysis before form correction.

The results of measurement may be analysed using the option SHAPE CONTROL. If compensation is required, an appropriate function is initialised, and the grinding process is finished with the compensation procedure described in [11]. Otherwise, the final dimension and shape is obtained without compensation.

The measurement results can be presented both in orthodox, and in radial coordinate systems illustrated in Figures 3 and 4 . It should be noted that there is substantial difference between out-of-roundness values of the main journals and crank pivot. Before form compensation, the former is between 0.01 and $0.02 \mathrm{~mm}$, while the latter are in range 0.07-0.09 $\mathrm{mm}$. Figure 5 presents an example of harmonic analysis.

\section{Measurement results and correction}

In the analysis, some additional parameters were measured and processed. It was checked, how machining speed effects on the geometrical accuracy of the main journals and crank pivots. Roughness was measured after grinding, to check how the surface is prepared for further hand polishing. The temperature was measured, so some deviations were possible to be contributed to the temperature gradients. Comparison with the reference measurement results of the gauge pivot was very helpful in the accuracy analysis. As a result, some recommendations on the temperature control were formulated. Fig. 6 shows the reference pivot used for the gauge calibration (diameter $480 \mathrm{~mm}$ ), and Fig. 7 presents the measuring arm equipped with the measurement prism, sensor and coolant channel.

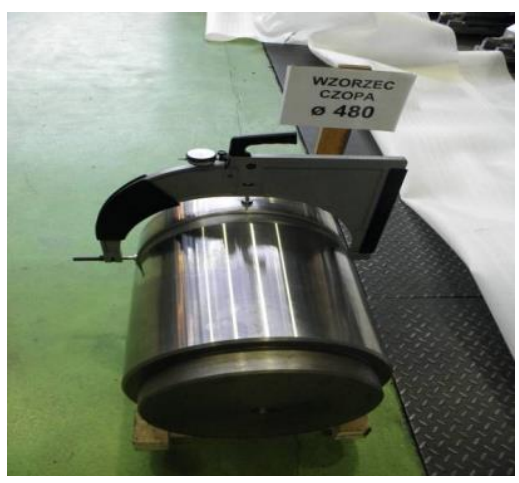

Fig. 6. Gauge pivot of diameter $480 \mathrm{~mm}$.

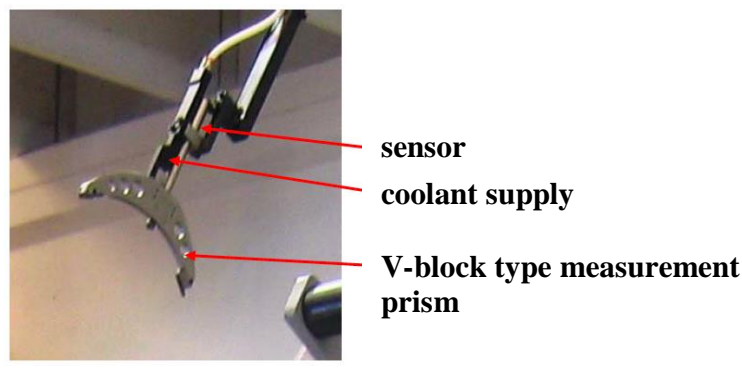

Fig. 7. Measuring arm [12].

Usually, uncertainty of measurement systems is evaluated considering either statistical data (type A method) or by scientific judgement based on all the available information (type B) [13]. It is applicable both for industrial accuracy tests [14] and for laboratory test rigs [15]. In some cases, it is necessary to develop a test method and to evaluate it [16]. There are also numerous 
papers dedicated to cylindricity measurement generally [17], and to the V-block measurement method [18]. Even though many factors that influence the performance of a roundness measuring instrument should be considered [19], including a roundness measurement algorithm [20], here, the most important was the random effect. Thus, measurement uncertainty was calculated using type A method. The standard uncertainty $u$ was determined statistically as follows:

$$
u=s_{x}=\sqrt{\frac{\sum_{1}^{n}\left(\bar{x}-x_{i}\right)^{2}}{n-1}}
$$

which is uncertainty of a single measurement result expressed through the standard deviation. The mean value of $x$ was calculated typically:

$$
\bar{x}=\frac{1}{n} \cdot \sum_{1}^{n} x_{i}
$$

In case of the series of $n$ repetitions, the obtained mean value has smaller uncertainty than a single measurement result. It can be considered as follows:

$$
u_{\text {mean }}=u / \sqrt{n}
$$

Some of measurement results with accuracy analysis are presented in Table 1.

Uncertainty of the mean value $u_{\text {mean }}$ is much smaller than that of single measurement $u$ because of large number of measurement points. However, in case of such a significant element as a crankshaft, every single point should be measured accurately, which can eliminate possible failure caused by unnoticed and averaged error.

In some cases, where form compensation was applied, the form deviations were reduced substantially. For instance, in the case presented in Figure 4, peak-topeak deviation was $13.74 \mu \mathrm{m}$ with its maximum 6.87 $\mu \mathrm{m}$. After form compensation and subsequent finishing grinding, respective values were reduced to $3.53 \mu \mathrm{m}$ and $1.84 \mu \mathrm{m}$. The graphical representation of measurement results after compensation is shown in Fig. 8.

Similarly, substantial reduction of form deviation was obtained in the crank pivot after form correction. Measurement after grinding without correction revealed peak-to-peak deviation of $61.07 \mu \mathrm{m}$ with its maximum $30.37 \mu \mathrm{m}$. When form compensation was made, subsequent finishing grinding provided results $16.77 \mu \mathrm{m}$ and $8.14 \mu \mathrm{m}$, respectively. The graphical representations before and after compensation are presented in respective Figures 9 and 10 .

The examples above demonstrate how the form after grinding may be affected by deflexion of the immense mass of the crankshaft. The introduction of the compensation procedure can reduce form deviation of the crank pivot down to $30 \%$ of the value obtained without compensation, and the one of the main journals down to $27 \%$ of the initial value obtained without

\begin{tabular}{|c|c|}
\hline Crankshaft type & $8 \mathrm{PC}$ \\
\hline Signature & $28501 / \mathrm{C} 1$ \\
\hline Number of measuring points & 172 \\
\hline $\begin{array}{l}\text { Recommended number of } \\
\text { measuring points (TR110) }\end{array}$ & 187 \\
\hline $\begin{array}{l}\text { Approximation error for } \\
\text { different than recommended } \\
\text { number of measuring points }\end{array}$ & 0.0120 \\
\hline Peak to peak distance (min) & $0.28 \mu \mathrm{m}$ \\
\hline Peak to peak distance (max) & $1.2 \mu \mathrm{m}$ \\
\hline Peak to peak distance (mean) & $0.44 \mu \mathrm{m}$ \\
\hline $\begin{array}{c}\text { Standard deviation for a single } \\
\text { measurement }\end{array}$ & $0.0955 \mu \mathrm{m}$ \\
\hline $\begin{array}{c}\text { Standard deviation for } \\
\text { a population }\end{array}$ & $0.0952 \mu \mathrm{m}$ \\
\hline $\begin{array}{c}\text { Standard deviation for a mean } \\
\text { value }\end{array}$ & $0.0073 \mu \mathrm{m}$ \\
\hline Probability & 0.95 \\
\hline Confidence coefficient & 0.1 \\
\hline $\begin{array}{l}\text { Quantile of the normal } \\
\text { standardized distribution }\end{array}$ & 1.6449 \\
\hline $\begin{array}{l}\text { Standard uncertainty for the } \\
\text { single measurement } u\end{array}$ & $0.10 \mu \mathrm{m}$ \\
\hline $\begin{array}{l}\text { Uncertainty for the mean value } \\
\qquad u_{\text {mean }}\end{array}$ & $0.01 \mu \mathrm{m}$ \\
\hline
\end{tabular}
compensation.
Table 1. Example of obtained results.

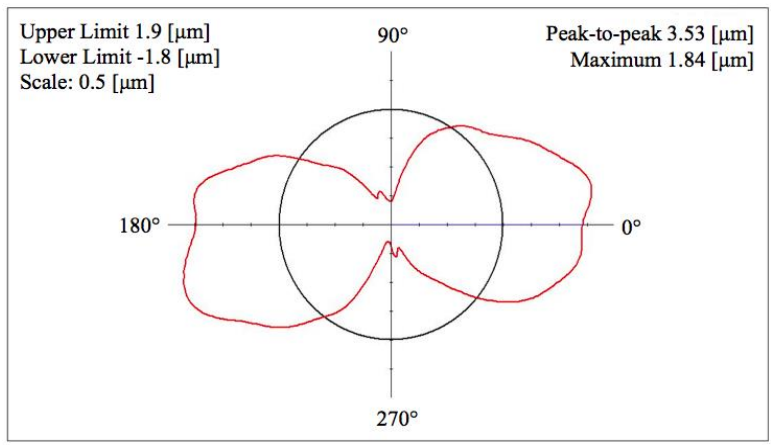

Fig. 8. Main journal form deviation measurement results after form correction.

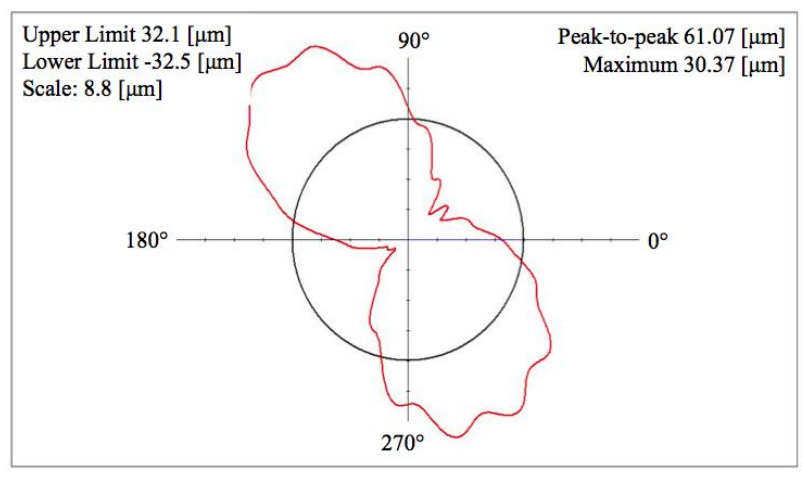

Fig. 9. Crank pivot form deviation measurement results before form correction. 


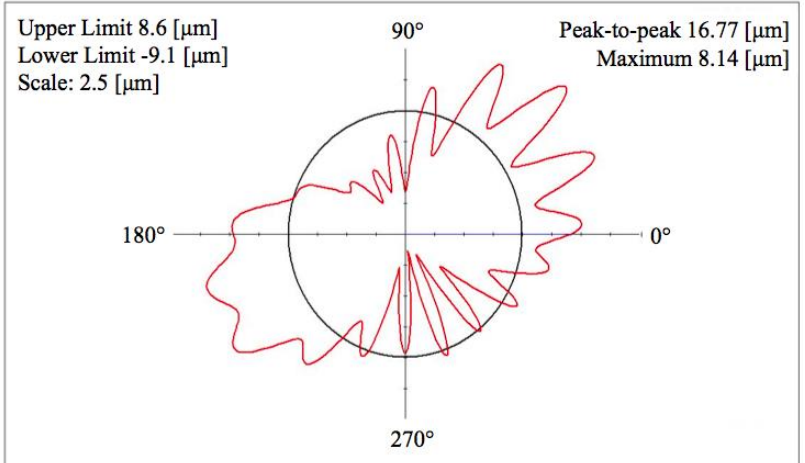

Fig. 10. Crank pivot form deviation measurement results after form correction.

\section{Conclusions}

Presented algorithm based on the Marposs measurement and control system proved to be very successful in the grinding process of marine diesel engine crankshaft. Measurement devices incorporated into the system provide accurate and reliable data that are used in further technological procedures and operations. Standard uncertainty of a single measurement $u$ was as small as $0.10 \mu \mathrm{m}$ for maximal peak-to-peak distance $1.2 \mu \mathrm{m}$. Measurement in 172 points provided uncertainty for the mean value $u_{\text {mean }}=0.01 \mu \mathrm{m}$.

The described program is applied for both main journals and crank pivots. There are some differences only in the values of speed and feeding depth. Compensation of deformation caused by deflexion enabled to obtain substantially smaller form deviation of pivots and journals, ca. $30 \%$ of the values obtained by grinding without compensation.

The project was co-financed by the Polish Ministry of Education (6 ZR8 2009 C/07162) and company Celsa „Huta Ostrowiec" Sp. z o.o.

\section{References}

1. Z. Siemiątkowski, M. Rucki, S. Lavrynenko, Investigations of the shrink-fitted joints in assembled crankshafts, Proceedings of the 7 th International Conference on Mechanics and Materials in Design M2D2017, Albufeira/Portugal 11-15 June 2017, p. 1155

2. M. Fonte, P. Duarte, V. Anes, M. Freitas, L.Reis, Eng. Fail. Anal. 56, 51 (2015)
3. J.F.G. Oliveira, E.J. Silva, J.J.F. Gomes, F. Klocke, D. Friedrich, CIRP Annals 54, 269 (2005)

4. F.S. Silva, Key Engineering Mat. 245-246, 351 (2003)

5. K. Król, M. Wikło, K. Olejarczyk, K. Kołodziejczyk, Z. Siemiątkowski, W. Żurowski, M. Rucki, J. KONES Pow. Transp. 24 (2), 117 (2017)

6. N.Y. Shen, J. Li, X. Wang, J. Ye, Zh. Yu, App. Mech. Mater. 532, 285 (2014)

7. P. Wolszczak, K. Łygas, G. Litak, Adv. Sci. Technol. Res. J. 11 (1), 96 (2017)

8. W. Grzesik, Mechanik 8-9, 587 (2015)

9. B. Gapinski, M. Rucki, The Roundness Deviation Measurement with CMM, Proceedings of IEEE International Workshop on Advanced Methods for Uncertainty Estimation in Measurement, Sardagna, Italy, 21-22 July 2008, pp. 108-111

10. J.Cz. Jermak, M. Rucki, Metrol. Meas. Sys. 23(1), 85 (2016)

11. 3. Семёнтковский, Д. Морозов, Е. Наройчик, М. Руцкий, С. Лавриненко, Інформаційні технології: наука, техніка, технологія, освіта, здоров'я, MicroCAD-2017, Харків, 19.05.2017, Ч. І, стр. 183

12. Manual for grinding machines DB12500-CNC

13. "Guide to the Expression of Uncertainty in Measurement," International Organization for Standardization (ISO), 1995

14. J. Józwik, E. Jacniacka, D. Ostrowski, ITM Web Conf. 15, 04005 (2017)

15. Cz.J. Jermak, M. Jakubowicz, J. Derezynski, M. Rucki, Int. J. Precis. Eng. Manuf. 18 (4), 479 (2017)

16. J. Jozwik, P. Piesko, G. Krajewski, Eksploat Niezawodn. 3, 10 (2010)

17. K. Stepien, Precis Eng. 38 (3), 697 (2014)

18. S. Adamczak, D. Janecki, K. Stepien, Measurement 44 (1), 164 (2011)

19. A.P. Raj, A.K. Ravi, P.B. Dhanish, Measurement 131, 193 (2019)

20. T. Widmaier, B. Hemming, J. Juhanko, P. Kuosmanen, V.-P. Esala, A. Lassila, P. Laukkanen, J. Haikio, Precis Eng. 48, 181 (2017) 